International Journal of Linguistics, Literature and Translation

ISSN: 2617-0299 (Online); ISSN: 2708-0099 (Print)

DOI: 10.32996/ijltt

Journal Homepage: www.al-kindipublisher.com/index.php/ijltt

IJLLT

\title{
The Status of English in Bahrain: A Quantitative Analysis of Domains Uses and Attitudes
}

\author{
Abdulaziz Bulaila' 9 (D) $\triangle$ and Imed Bin Abdallah Sdiri² 9 (D) \\ ${ }^{1}$ Associate Professor, English Language and Literature Department, College of Arts, University of Bahrain. Kingdom of Bahrain \\ ${ }^{2}$ Senior education specialist, Ministry of Education, and part-time lecturer at the University of Bahrain and Abdulla Bin Khaled \\ College for Islamic Studies. Kingdom of Bahrain
}

$\triangle$ Corresponding Author: Abdulaziz Bulaila, E-mail: abulela@uob.edu.bh

ARTICLE INFORMATION ABSTRACT

Received: March 15, 2021

Accepted: April 23, 2021

Volume: 4

Issue: 4

DOI: 10.32996/ijllt.2021.4.4.27

\section{KEYWORDS}

Kingdom of Bahrain, English

Language, uses, attitudes,

quantitative analysis
The use of the English language in the Kingdom of Bahrain nowadays is widespread in various domains and for multiple purposes. However, there is no consensus among language experts in the country on what status English holds in reality. By using a survey questionnaire, the study explored the domains where English is used, how frequent that use is, and how it is being perceived by Bahraini students and working people in the public and private sectors. The analysis of the collected data helped this research study to assertively conclude that the status of English in Bahrain is shifting and that today it stands as a well-established second language with a variety of functions. This study has even revealed that Arabic, the official language of the country, is being relatively displaced by English in more than one context, including those where Arabic was traditionally the dominant language. It is hoped that such significant findings would help policymakers in Bahrain, especially those responsible for educational policies, to develop relevant language plans that are based on exact research findings. They would also help educational institutions at all levels, curriculum developers, textbook designers in Bahrain, the Arabian Gulf, and all over the world to design relevant language programs that reflect the needs of all Bahrainis and that are aligned with official language policies. Moreover, they would provide language researchers worldwide with valuable data so as to deeply understand the dynamics of English as a global language, gain further insight into the diverse factors that facilitate its expansion, and eventually manage to design more comprehensive reference frameworks and analytical models that could incorporate all this diversity.

\section{Introduction}

English in Bahrain is an important language which serves diverse functions in the daily lives and transactions of both Bahrainis and non-Bahrainis. One could even argue that speaking English at some level of competence is a necessity in Bahrain these days as it is highly used in diverse contexts and for multiple purposes. Besides, it seems that the use of English in Bahrain is increasingly becoming more and more widespread. Gomaa (2020, p. 27) argues that "English is common and most-well-spoken in Bahrain. It is a mandatory second language in educational institutions. Nonetheless, when academically discussing the status of English in Bahrain and the various functions it serves, some contradictory descriptions are repeatedly used to portray its position. For instance, some language practitioners at all levels often refer to English as a second language without estimating the implications of such labels. "Others, however, consider English a foreign language and equate it with other languages such as French, Chinese, Spanish, and Japanese, although the status of English in the country clearly goes far beyond those languages. In reality, English is omnipresent in Bahrain, but how frequent its use is, why people use it, and how they perceive it are unanswered questions that presumably require urgent investigation. One could even cautiously claim that, apparently, there is a gap in our knowledge about English in Bahrain, and this gap is clearly reflected in how it is variedly described by some public institutions in the country. For instance, Bahrain Teachers' College (2012) claims that "the Ministry of Education has made a commitment to

\section{K C AL-KINDI CENTER $\mathbf{R}$ D FOR RESEARCH AND DEVELOPMENT} Your gateway to world-class research

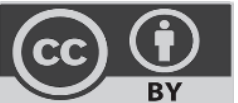

Published by Al-Kindi Center for Research and Development, London, United Kingdom. Copyright (c) the author(s). This open access article is distributed under a Creative Commons Attribution (CC-BY) 4.0 license 
preparing students for participation in the global knowledge economy through delivering English as Second Language training to students from Grade 1 on." In the official Syllabus for Basic Education published by the Directorate of Curricula, however, English is recurrently described as "a foreign language" (2005, p 6) which is taught from grade 1 onwards. Shura Council (2015) states on its official website that "English [...] is widely understood and spoken, and commonly used in business" without employing the same terms used by some other official institutions in the country.

This lack of a clear understanding of what position English holds in Bahrain is further illustrated by how it is referred to by other institutions in the country. The Education and Training Quality Authority (2010, p 7) reports that at the University of Bahrain Cin most colleges such as Engineering, IT, Science, Business Administration, Applied Studies and Bahrain's Teachers College, English is the official language of instruction," a description which entitles English to enjoy a very high status in the country. The Department of English Language and Literature at the University of Bahrain (2016) states that it "provides students of English Language and Literature with the opportunity to study other foreign languages in addition to English such as French, German or Japanese." The Ministry of Foreign Affairs (2015), however, stresses the role English plays in the domains of business and education by stating that it "is widely used in business and is compulsory in schools."

Gomaa (2017) studies the use of English in the Bahraini Linguistic Landscape. He maintains that "English has emerged as a lingua franca between multilingual speakers in Bahrain" (Gomaa 2017, p. 271). Resorting to previous research studies to better understand the linguistic scene in Bahrain, and especially the status of English, leads nowhere as, to our knowledge, there is no previous studies other than those conducted by Gomaa (2017) and Gomaa (2020), in Bahrain which have attempted to understand the dynamics of English in the country. Besides, international literature does not appear to do justice to the rich linguistic situation in Bahrain and the whole Arab Gulf region. Although examining the status of English in the world is a recurrent issue in contemporary linguistics, the number of research studies which have empirically investigated the language situation in the Arab Gulf region is unexpectedly very limited. It is true that a few research studies have investigated the status of English in Qatar and Dubai, but the situation of English in Bahrain seems to be ignored, although the country presents an excellent context for various insightful research studies.

To sum up, investigating the status of English in Bahrain and understanding how it functions in the country is an essential multifaceted issue which requires systematic investigation. It is evident that there is no agreement on what English represents in Bahrain or how it is used by Bahrainis. Therefore, a well-structured study that attempts to empirically examine its status would definitely provide valuable data, which could encourage further research and enlighten several language experts who are keen on understanding the linguistic scene in Bahrain and the whole Arab Gulf region. In fact, it would be practically impossible to adopt solid language policies, develop consistent English language curricula, or design relevant teaching and learning materials without understanding what status English holds in the country, how people use it, and how they view it.

\section{Literature Review}

Determining the status of the English language within a country is not an easy task despite the fact that labels or classifications like "first language", "second language" or "foreign language" are often used by language practitioners. Kachru (1992) conceived the idea of the 'three concentric circles of the English language. According to this model, the status of English within countries is linked to certain historical, social, and political realities. The inner-circle corresponds to the United Kingdom, the United States, Australia, New Zealand, Ireland, Anglophone Canada, and some of the Caribbean territories. In this first circle, English is used as a first language. The second circle is called "the outer circle", and it corresponds to countries where English is the second language as it plays key historical, political and institutional roles. This circle includes India, Nigeria, the Philippines, Bangladesh, Pakistan, Tanzania, Kenya, non-Anglophone South Africa and Canada, etc. The last circle is the expanding circle. It includes countries where English is referred to as a foreign language because it plays no historical or governmental roles. This encompasses countries like China, Russia, Japan, most of Europe, Korea, Egypt, etc.

\begin{tabular}{|l|l|l|}
\hline \multicolumn{1}{|c|}{ Table 1: Kachru's Model (1985) } \\
\hline \multicolumn{1}{|c|}{ Inner Circle } & \multicolumn{1}{c|}{ Outer Circle } & \multicolumn{1}{c|}{ Expanding Circle } \\
\hline $\begin{array}{l}\text { English as a native language } \\
\text { (ENL) }\end{array}$ & $\begin{array}{l}\text { English as a second language } \\
\text { (ESL) }\end{array}$ & $\begin{array}{l}\text { English as a foreign } \\
\text { language (EFL) }\end{array}$ \\
\hline Language Users & Language Users & Language Learners \\
\hline Norm providing & Norm developing & Norm dependent \\
\hline $\begin{array}{l}\text { English acquired at home, at } \\
\text { school and in wider society }\end{array}$ & $\begin{array}{l}\text { English acquired at school and in } \\
\text { wider society }\end{array}$ & English acquired at school \\
\hline $\begin{array}{l}\text { English used for international } \\
\text { communication }\end{array}$ & $\begin{array}{l}\text { English used for international } \\
\text { communication }\end{array}$ & $\begin{array}{l}\text { English used for } \\
\text { international }\end{array}$ \\
\hline
\end{tabular}




\begin{tabular}{|l|l|l|}
\hline & & communication \\
\hline Standard English & $\begin{array}{l}\text { Deviations from Standard } \\
\text { English seen as innovations }\end{array}$ & $\begin{array}{l}\text { Deviations from Standard } \\
\text { English seen as errors }\end{array}$ \\
\hline
\end{tabular}

Using Kachru's model to determine the status of English in Bahrain reveals that his work does not fully apply to the Bahraini context. In fact, one could say that Bahrain challenges Kachru's model by sharing features of both ESL and EFL. This, actually, means that using Kachru's criteria to determine the actual status of English in Bahrain does not lead to precise descriptions as the status of English in Bahrain apparently falls in between the second and third circles. To put it more clearly, it can be noticed that English in Bahrain is learnt at school and, to some extent, widely used by the wider community. Additionally, it could be observed that English in the country is, in varying ways, used for internal and external communication. Nonetheless, claiming that Bahrainis have developed their own English language norms is a judgment which requires further investigation.

Relatively in line with Kachru, Graddol (2000) clearly distinguishes between areas or countries where English is used as a foreign language (EFL) and those where it is used as a second language (ESL). He explains that in EFL areas, English is primarily used to communicate with speakers from other countries. In ESL areas, however, it is used for "internal (intranational) communication" (Graddol, 2000, p 11). He adds that in areas where English is used "extensively" as a second language, a distinct variety of English is usually developed. Graddol adds another main feature that distinguishes an EFL speaker from an ESL speaker. For him, if "English is used within the community (country, family)" and "forms part of the speaker's identity repertoire" (Graddol, 2000, $p$ 11), then it could be referred to as a second language. In addition to making clear distinctions between EFL and ESL, Graddol argues that the status of English within certain countries, like the United Arab Emirates, is in the process of shifting from EFL to ESL, mainly as a result of the growing use of English for international communication as well as for professional and educational purposes. In fact, in a book published by the British Council in 2006, Graddol goes a bit further by arguing that English could no longer be referred to as a foreign language because of its extensive use and widespread presence on a global scale. He states that "there is an extraordinary diversity in the ways in which English is taught and learned around the world, but some clear orthodoxies have arisen. 'English as a Foreign Language' has been a dominant one in the second half of the 20th century, but it seems to be giving way to a new orthodoxy, more suited to the realities of global English (Graddol, 2006, p 82).

Unlike Kachru who has divided the status of English within societies into three categorical circles, Bhushan (2011) stresses the centrality of social context and its impact on learning and teaching languages. He considers that languages are taught and learnt to establish contact and communication across language boundaries. He argues that language use varies from one context to another, and that the more people vary their use of that language, the more that language becomes influential in that society and culture. This same idea is expressed by Longcope (2008) in his "Differences between the ESL and EFL Language Learning Contexts." Longscope considers that the main indicator or factor which distinguishes a second language from a foreign language is the social context of language or what could be referred to as the environment in which that language is used. Longcope (2008) as well as Hakan (1980) argue that the environment strongly influences language learning as in an L2 context, students receive more comprehensible input and produce more comprehensible output compared to those who study and live in an $\mathrm{FL}$ context. The current research study, consequently, is going to investigate the status of the English language in Bahrain by analyzing the scope and frequency of its use in various contexts as well as people's attitudes towards it. It is envisaged that proving that the use of English in Bahrain is not limited to the school environment will challenge any description of its status as a foreign language. Besides, it is hoped that understanding how widespread English is in the Bahraini society will help to determine its actual status and, thus, consider the possibility of labelling it as a second language in the country. Other researchers, like Van Patten and Lee (1990) and Ringbom (1980), make a distinction between second language acquisition and foreign language learning. For Ringbom, the first obvious and significant difference is that a second language is acquired, unlike the foreign language which is learnt. This difference implies that a second language could be naturally learnt without systematic education. A foreign language, however, cannot be learnt without systematic instruction and guidance. The focus here is on the prevailing learning situation, not directly on the learning process itself.

\begin{tabular}{|l|l|}
\hline \multicolumn{2}{|c|}{ Table 2: Situational Differences between SLA and FLL (Ringbom, 1980) } \\
\hline Second Language & Foreign Language \\
\hline More time is spent on acquisition & Less time can be spent on learning \\
\hline $\begin{array}{l}\text { Compared to FLL, the input is rich and } \\
\text { varied. The learner is exposed to samples of } \\
\text { language that are little organized. }\end{array}$ & $\begin{array}{l}\text { The learner is exposed to highly structured, selected } \\
\text { and sequenced input. }\end{array}$ \\
\hline $\begin{array}{l}\text { Mainly unguided discovery: acquisition from } \\
\text { peers, possibly supplemented by classroom } \\
\text { teaching. }\end{array}$ & $\begin{array}{l}\text { Guided discovery: the learning mainly takes place in } \\
\text { artificial classroom situations and/or by study at } \\
\text { home. Little or hardly any learning from peers. }\end{array}$ \\
\hline
\end{tabular}




\begin{tabular}{|l|l|l|}
\hline A genuine need for oral communication & The dependence on written material in an average \\
exists: the oral skills are all important. & $\begin{array}{l}\text { classroom situation and the absence of a genuine } \\
\text { Comprehension of natural speech is } \\
\text { particularly important from the very for communication make oral skills less } \\
\text { beginning. }\end{array}$ & $\begin{array}{l}\text { important. The sequencing of skills depends on the } \\
\text { aims and the methods of the course. }\end{array}$ \\
\hline
\end{tabular}

In line with Ringbom, Moeller and Catalano (2015) also argue that a distinction is often made between foreign language learning and second language acquisition. They explain that a foreign language is largely learnt in a school-based environment. Second language acquisition, however, is a term which is used to denote the learning of a language "naturally" and "without formal instruction." Other researchers, however, do not focus on the notion of acquisition while talking about FL or SL varieties. They just make a distinction between the two varieties depending on their corresponding status within a given context. For instance, in his essay "The Sociology of Language Teaching and Learning" (2011) the Indian researcher Ravi Bhushan explains that a distinction is often made between 'second language' and 'foreign language' in pedagogy and sociolinguistics. For him, a 'second language' is learned for use in an area where that language is not generally spoken. The key term here is 'use'. A second language is, therefore, a language which learners learn within schools and additionally use it outside their classrooms. Arguably, English in countries such as India, Pakistan, Bangladesh, the Philippines, the Scandinavian countries and the Netherlands can be considered as a second language for many of its speakers because they learn it young and use it regularly. Edwards (2014, p 77) adds another criterion to differentiate between EFL and ESL varieties. He states that "a precondition for ESL status is that English is used by large parts of the population, not only by the elite (as is the case in EFL)." This, obviously, drives us to conclude that if we prove that English in Bahrain is widely and frequently used outside the educational context, then this implies that it functionally holds the status of a second language.

This hypothesis, however, should not be considered in a simplistic way as other researchers, like Mollin (2006), propose a variety of conditions to describe English as a second language variety. Mollin (2006, p 52-54), for instance, suggests a catalogue of criteria or conditions that are necessary to regard English as a second language variety. These criteria are related to three key requirements: scope of function, the presence of a nativized form, and the recognition/acceptance of the local variety's norms. And as outlined in Table 3, Mollin's criteria target an ideal language situation in which one expects to find all the specified criteria. However, Molin does not state how we would describe the status of English within a certain context if some of her criteria are not accessible.

\begin{tabular}{|l|l|}
\hline Table 3: Criteria for ESL-status (Mollin, 2006, p 52) \\
\hline \multirow{4}{*}{ Function } & Extensive bilingualism \\
\cline { 2 - 3 } & Use in the domain of education \\
\cline { 2 - 3 } & Use in the domain of administration \\
\cline { 2 - 3 } & Use in the media \\
\cline { 2 - 3 } & Use as a contact code \\
\cline { 2 - 3 } & Use in creative writing \\
\hline \multirow{4}{*}{ Attitude } & Extended register and style range \\
\cline { 2 - 3 } & Distinctive lexicon, phonology, syntax, discourse style \\
\cline { 2 - 3 } & Characteristics must be communal, not idiosyncratic \\
\cline { 2 - 3 } & New features must be systematic \\
\cline { 2 - 3 } & No gap between performance model and behavior \\
\cline { 2 - 3 } & Acceptance of the local variety and its label \\
\hline & Beginning codification and official recognition of the variety \\
\hline
\end{tabular}

As a matter of fact, the present paper is going to consider the application of some of the above criteria to determine whether English in Bahrain is a foreign or a second language. It will attempt to collect data relating to the use of English in society, the functions it serves, its frequency, and people's attitudes towards its use. It is worth noting, however, that the debate concerning the status of English within countries is not limited to second and foreign language classifications. Edgar Schneider (2003), for instance, devised an influential framework which he called the "Dynamic Model of the Evolution of Postcolonial Englishes" to examine how English has developed within post-colonial contexts. This model links the spread of English to colonization and the role colonizing settlers played in disseminating the use of English among indigenous people.

This framework might look useful in the Bahraini context because the country was once a British protectorate. Schneider (2003) argues that postcolonial varieties of English have gone through five developmental phases that are shaped by four interrelating parameters. In its essence, Schneider's Dynamic Model is based on the fact that the more the new settlers or colonizers interact 
with the indigenous people, the more they are likely to disseminate their language. Additionally, this model shows that the use of English for administrative, educational, and legislative purposes forces the indigenous people to learn it. Thus, English gradually becomes deeply rooted in the colonized land. Time, or history, is another factor which enhances the process of spreading English within the colonized land. As the settlers' bonds with their homeland wane and diminish, their belonging to the colonized land strengthens. This gradual shift in identity reinforces the relationships between the settlers and the natives, resulting in the emergence of new local norms or language rules.

It may seem logical, then, to refer to Schneider's model to understand the stages English in Bahrain has gone through to achieve its current status. As it is clearly documented in historical records, Bahrain has fallen under the British 'rule' from 1820 to 1971 (Al-Nabi, 2012), and that the first significant contact of Bahrainis with English was through the British agents who represented the British interests in the region. However, as it could be noticed today English has not become the native language of Bahrainis. This could be partially explained by the fact that the number of British settlers who came to Bahrain was very limited and that their mixing with the indigenous people (Bahraini Arabs) was also narrow. Al Nabi $(2012, \mathrm{p} \mathrm{33})$ indicated that the number of British settlers in Bahrain was 2513 in 1959, 2802 in 1965, and 2919 in 1971. Additionally, he stated that "Juffair was selected for the establishment of the British military headquarters in 1927" ( $p 33$ ) and that Awali "was populated by Europeans only" ( $p$ 27), which implies that the British did not fully mix with the locals, and that there were some social boundaries. In fact, this idea is further defended by analyzing how the Bahraini population was geographically distributed in the country. Al-Nabi $(2012$, p 27) explains that "The overall picture shows that in 1971, 75\% of the Bahraini population were concentrated in seven towns," and Juffair and Awali were not in the list of these seven towns. Thus, one could argue that unlike what Schneider proposed in his Dynamic Model, Bahrain did not follow the dynamism which he expected to happen in any colonial setting.

Besides the social and geographical boundaries that existed between the British and Bahrainis, historical records show that the British did not take full control of the country and that legislation, education, and administration were mainly in Arabic, the actual official language of the country. This implies that English in Bahrain has not followed the five stages included in Schneider's model. It has rather developed as a result of other political and sociolinguistic variables which Schneider's framework did not include or consider. And as explained by Edwards (2014) in his investigation of the status of English in the Netherlands, Schneider's model cannot be used to explain "other settings in which English has taken root." This model, arguably, overlooks key variables that have had an impact on the spread of English worldwide. These mainly include globalization, national language planning, and education.

\section{The Study}

There is no clear description of or common agreement on what position English occupies in Bahrain today. It is often referred to in various ways that do not thoroughly and precisely reflect how it is actually used and perceived by Bahrainis. Although English is widely recognized as the language of business in the country, it can be easily observed that its scope goes far beyond the business domain. Additionally, using the term "foreign language" to describe its status is an issue that requires deeper investigation as the use of English in Bahrain is not confined to the educational context only. In fact, there is no previous study which has attempted to document the status and scope of English in Bahrain by analyzing, for instance, how often, where, and why English is used or how it is perceived by Bahrainis. 'Do Bahrainis use English at home, how often, and why?' are important questions that are worth investigating if we aspire to construct a comprehensive and rigorous understanding of this language in Bahrain. It is also crucial to analyze the language situation in Bahrain after decades of continuous educational and economic reforms in the country. Because the government has implemented a series of projects that aimed at promoting the status of English in the country and because there are several indicators which point to the growing use of English in the country, it would be very useful to implement a large-scale study that targets mapping out the presence of English in the country and understanding its dynamics.

The current research paper attempts to fill in the gap in our knowledge about the status of English in Bahrain. It aims at providing a clear understanding of the various domains in which English is used, the frequency of Bahrainis' use of English, and their attitudes towards it. It will also attempt to identify any elements of language shift by analyzing how young people (aged 16-24) and employed adults (aged 45-60) differ in their use of and attitudes towards English. It is hoped that the data collected will eventually offer enough evidence to rigorously describe the status of English in Bahrain and determine the factors that have led to such a status. To provide a clear answer and come up with reliable results that could add to our knowledge about English and our understanding of its status in Bahrain, three questions are systematically, purposefully, and successively asked:

(10 What are the main domains in which English is used by Bahrainis?, (2) How frequently is English used by Bahrainis?, and (3) What are the attitudes of Bahrainis towards the use of English?

The three questions are answered according to the three background variables of the respondents. These include gender (male female), education sector (private - public), and work sector (private - public). It is hoped that this paper will provide a 
comprehensive picture of the use of English in Bahrain. It will establish a solid background understanding that could help us to determine the actual status of English in Bahrain. As a matter of fact, the three questions have a descriptive nature. It is expected that the findings will lead to some practical recommendations that have the potential to develop various areas related to English language use and language policies in Bahrain. These include language planning, curriculum development, teaching methodology, and textbook design. Furthermore, the findings would assist other researchers who are interested in mapping out the presence of English worldwide in gaining a further understanding of the expansion of English as a world language in various parts of the globe.

\section{Methods and Procedures}

To address the research questions, a quantitative methodology is used to collect data. A survey questionnaire comprising 30 questions was randomly administered to a randomly selected sample of respondents in March and April 2017. The instrument is divided into four main sections: 1- background information, 2- Domains of English, 3- Frequency of the use of English, and 4Attitudes towards English. The target population was divided into two main groups. These were divided into various subgroups or strata according to three background variables that include gender (male - female), education sector (private - public), and work sector (private - public). The size of the final sample was initially determined by using an online application called Sample Size Calculator that was developed by the American Survey Software Company Creative Research Systems. The selected confidence level is $95 \%$, the confidence interval is 5, and the target population as indicated by the official Central Informatics Organization (2013) Bahrain in is 614,830. Thus, the minimum sample size needed as required by the selected Sample Size Calculator is 384 respondents. However, the final sample consisted of 451 respondents. This variation is caused by the fact that the number of respondents within each subgroup varied because response rates were different. Moreover, to make sure that the data collected are relatively representative of each subgroup, a minimum number of 30 respondents was determined, as indicated in some applied linguistics research books, including the one published by Dornyei (2007). Thus, in all subgroups the number of respondents is always above 30 .

The first main group corresponds to secondary school and university students who are aged 16 to 24 . This group was evenly divided into different subgroups according to gender (male-female), level of education (secondary-university), and education sector (private-public). University students were evenly grouped in terms of gender. Secondary school students, however, were divided into two subgroups in terms of the education sector (public-private). The rationale for this choice is to investigate any variations in the use of English between those who go to public schools and those who choose to join private schools. Analyzing such variations would provide a relatively comprehensive understanding of the workings of English in Bahrain and the main factors that have an impact on how it is used in the country.

The second main group corresponds to employed adults who were born before the independence of the country in 1971. This group was evenly divided into four subgroups according to gender (male-female) and work sector (public-private). Targeting this group would help this paper to collect data regarding the status of English in both the public and private sectors, and to identify any elements of language shift. Because the two main groups (born after the year 2000, and born before the independence in 1971) belong to two different historical eras, it is hoped that the findings would reveal probable changes in the status of English in Bahrain by comparing variations in the frequency of use of English and their attitudes among the two groups.

\section{Results and Discussion}

\subsection{Domains of English}

This section attempted to understand where English is used in Bahrain and how frequent that use is within different domains. As explained by Edwards (2014, p 77) "a precondition for ESL status is that English is used by large parts of the population, not only by the elite (as is the case in EFL)." Thus, to grant English in Bahrain the title of a second language, it was essential to examine its "scope of function" as also suggested by Mollin (2006). Eight different domains were targeted. These included (1) work, (2) school or university, (3) government offices or ministries, (4) banks, post offices, or insurance agencies, (5) shops, stores, malls, restaurants, or cafés, (6) hospitals, health centers, or clinics, (7) recreational places such as cinemas, theatres, or sports clubs, and (8) home. Overall, the results show that the use of English in the given domains is moderate in terms of frequency. This complex finding yields two facts. First, it is evident that Bahrainis use English in different domains outside the educational environment. Second, it is evident that Bahrainis use English at varying degrees of frequencies. Out of the eight domains which this study targeted, in only three domains the use of English was significantly frequent. These included (1) shops, stores, malls, restaurants, or cafés, (2) work, and (3) school or university. In fact, the high frequency of using English in these domains marks the three key functions which English in Bahrain serves. These are (1) the transactional function, (2) the occupational function, and (3) the educational function.

It is also essential to add that in all the domains which this study has targeted, the phenomenon of the non-use of English was almost always limited. Only a minority of respondents declared that they never use it. For instance, only $2.2 \%$ of working people 
stated that they never use it at work, $0.7 \%$ of students stated that they never use it where they study, $27.7 \%$ of all the respondents stated that they never use it in government offices or ministries, $22.8 \%$ never use it in banks, post offices, or insurance agencies, 2.7\% never use it in shops, stores, malls, restaurants, and cafés, 5.1\% never use it in hospitals, health centers, and clinics, $7.3 \%$ never use it in recreational places, and $24.9 \%$ never use it at home. This, simply, implies that English is, in reality, extensively used by Bahrainis in various domains. In fact, Bhushan (2011) argues that the more people vary their use of that language, the more that language becomes influential in that society and culture. However, it is always crucial to remind that this extensive use is limited in terms of frequency. Such findings are of paramount importance because they confirm the fact that English could not and should not be referred to as a foreign language in Bahrain for it is used by "large parts of the population" (Edwards, 2014) and its "scope of function" (Collin, 2006) proves that it serves diverse functions in the country. These basically include the educational, occupational, transactional, administrative, recreational, and social functions.

\subsection{Frequency of the use of English}

This section examined how often Bahrainis use English receptively and productively in their daily lives. Unlike the first section which focused on multiple domains, this one investigated the frequency of using English according to some basic skills that are associated with English language use. The composite mean (3.38) for questions 13-18 indicates that the frequency of using English is overall moderate. Nonetheless, mean calculations clearly reveal that there are two differing tendencies. First, the use of English is frequent while (1) watching films, TV programs, or YouTube videos, and while (2) searching information online. Second, the use of English is limited in terms of frequency (less frequent or not common) while (3) playing electronic games, (4) writing, (5) listening, and (6) reading. The results clearly show that the non-use of English phenomenon was almost always limited. Only a limited proportion of respondents declared that they never use English, whether receptively or productively. For example, $17.1 \%$ of all the respondents never listen to songs or radio programs in English; $4.2 \%$ never watch films, TV programs, or YouTube videos in English; 20.5\% never read in English; 13.5\% never write in English; $6.4 \%$ never use English to search information on the internet, and $11.9 \%$ never use English to play computer or internet-based games. The rest of the respondents, however, do use English receptively and productively, but at varying frequencies. In fact, these findings signal the catalyst role globalization plays in disseminating English in Bahrain. The highly observable presence of English-speaking media and the extensive use of American social media platforms like Youtube, Facebook, Twitter or research engines like Google seem to have speeded up the process of spreading the use of English in Bahrain. This trend is, indeed, a global drive that is omnipresent in various countries around the world, including Finland, the Netherlands, the UAE, Sweden, Hong Kong, Malta, Malaysia, the Philippines, etc.

Another very important finding this study has unveiled is that the status of English is shifting in Bahrain. This shift in the use of English over time is traceable by comparing all students' and all working people's mean scores. It might be useful to remind that all students are aged 16-24, and that all working people are aged 45-60. These working people were all born before the independence of the country in 1971. Accordingly, one could argue that over time English has gained more ground in Bahrain because the younger generation seems to use English more frequently than the older generation. This process is accelerated or facilitated by different factors and variables. First, the de facto language planning policies which the government of Bahrain officially implements, especially in the educational sector, encourage the spread of English in the country. Second, as explained earlier, globalization in its economic and cultural forms has also stimulated the use of English in Bahrain.

In addition to official language policies, which favor multilingualism, and the highly felt impact of globalization on the linguistic scene in Bahrain, there are other factors which have also made the spread of English possible in Bahrain. These include (1) gender, (2) private schools, and (3) private companies. The study has revealed that female respondents have scored higher means than their male counterparts. This, overall, indicates that women use English more frequently than men in Bahrain, which implies that women are facilitating the spread of English in Bahrain. This idea is, in effect, extensively debated in sociolinguistics. For instance, Labov (2001, p 501) argues that: "any theory of the causes of change must deal with the general finding that in the good majority of linguistic changes, women are a full generation ahead of men." He even describes women as leaders of linguistic change "with a particular ability to confront established norms and the motivation to defy them." He adds (2001, p 516) that because they are inclined to show "a larger pattern of upward social mobility" they embrace language change and lead it. Thus, one could argue that the spread of English in Bahrain is also linked to gender, as women's quest to show social improvement incites them to use another language other than Arabic.

In addition to gender, private schools seem to play a reckonable active role in spreading English in Bahrain. Private school students have unanimously scored higher means than their counterparts in public schools. This signifies that private school students, overall, use English more frequently than public school students, which suggests that private schools are actively contributing to the spread of English in Bahrain. This trend might have an impact on the whole linguistic scene in Bahrain considering the fact that $39.64 \%$ of Bahraini students go to private schools, and that most of these private institutions extensively depend on English as the main language of instruction and even communication. 
In addition to women and private schools, private companies seemingly act as environments which boost the spread of English in Bahrain. Respondents working in private companies have scored higher means than their counterparts in public institutions. This suggests that the use of English in the private sector is more frequent than in the public sector, which implies that private companies are actively contributing to the spread of English in Bahrain. In fact, in 2016 the total size of the Bahraini workforce in both the public and private sectors was 159,711 employees (Labour Market Regulatory Authority, 2016). Out of these, 66,205 employees work in the public sector and 103,537 work in the private sector, which means that $64.83 \%$ of all active Bahrainis work in the private sector. These Bahrainis seem to use English more frequently than their counterparts in the public sector, and because of their relatively big size they are expected to further spread the use of English in Bahrain. Interpreting statistics released by the Labour Market Regulatory Authority (2016) helps a lot in gaining a deeper insight into the dynamics of English in Bahrain.

As mentioned earlier, the number of Bahrainis working in the private sector is 103,537 . These, however, form a minority in the private sector as the total size of the workforce in this sector is 577,655 workers, which implies that Bahrainis constitute only $17.92 \%$ of the entire workforce in the private sector. The remaining 474,118 of workers are non-Bahraini immigrants, and most of them come from Asian countries (mainly India, Bangladesh, Sri Lanka, and the Philippines) where English enjoys an advanced status. These valuable findings are highly significant because they prove that immigration is another factor which accounts for the spread of English in Bahrain.

Another issue this paper has investigated is the scope of the housemaids' phenomenon in Bahrain and its impact on the linguistic landscape in the country. Over $73.4 \%$ of the respondents stated that they use English to communicate with housemaids, and official figures released by LMRA (2016) reveal that the number of domestic workers (including housemaids) reached 111,002 in the second quarter of the year 2016. This big number of domestic workers implies that another language other than Arabic is being daily used by Bahrainis at home. Accordingly, one could conclude that in addition to the de facto language policies, globalization, gender, private schools, and private companies, housemaids may also be referred to as accelerators or catalyzers that have facilitated the spread of English in Bahrain, knowing that most of these housemaids come from Asian countries that do not speak Arabic in its two varieties, Modern Standard Arabic or the Bahraini Arabic dialect.

\section{Attitudes towards English}

In the previous section, we have proved that English serves diverse functions in Bahrain. Besides that, we have shown that the receptive and productive use of English is relatively widespread in the country. In this section, we shall present and discuss the main findings relating to the respondents' attitudes towards English. In fact, Edwards (2014) and Mollin (2006) consider that the investigation of people's attitudes towards English is another criterion which determines what status English holds within a particular context. Overall, this paper has enough evidence to conclude that English in Bahrain is seen as a useful and attractive language. The majority of respondents view English as an important language. In fact, over $90 \%$ of all the respondents do believe that it is an important language for Bahrainis. Additionally, over $80 \%$ of all the respondents believe that Bahraini children should attend English-speaking schools, which reflects how much useful and beneficial English is for them, especially for educational purposes. Besides, over $75 \%$ of all the respondents believe that the importance of English will increase in the future. This positive attitude is clearly projected in the current language policies adopted by the government of Bahrain. The government has adopted two main language policies which valorize English by investing in private education and permitting some private schools to become bilingual institutions (Kanoo School, Ibn Khuldoon School, Hawar International School...) in conjunction with raising the status of English within public schools. It is important to note that all students in public schools study English from grade 1 in primary education for four to five periods a week until the end of secondary education.

Another valuable finding which this study has achieved is attitudinal divisions. Respondents seem to be divided in their attitudes over four issues. These include the use of English by public institutions, the use of English by private companies, its impact on Arabic, and its impact on the local culture. A detailed analysis of the previous four items reveals that neither those who agree nor those who disagree exceeded $50 \%$ of all the responses.

\begin{tabular}{|c|c|c|c|c|}
\hline Options & $\begin{array}{l}\text { Use of English by } \\
\text { public institutions }\end{array}$ & $\begin{array}{l}\text { Use of English by } \\
\text { private companies }\end{array}$ & $\begin{array}{c}\text { The impact of English } \\
\text { on Arabic }\end{array}$ & $\begin{array}{c}\text { The impact of English on } \\
\text { the local culture }\end{array}$ \\
\hline I strongly disagree & \multirow{2}{*}{$43.9 \%$} & \multirow{2}{*}{$30.4 \%$} & \multirow{2}{*}{$33.1 \%$} & \multirow{2}{*}{$34.5 \%$} \\
\hline I disagree & & & & \\
\hline I don't know & $18.8 \%$ & $20.2 \%$ & $21.1 \%$ & $23.1 \%$ \\
\hline I agree & \multirow{2}{*}{$37.3 \%$} & \multirow{2}{*}{$49.5 \%$} & \multirow{2}{*}{$45.8 \%$} & \multirow{2}{*}{$42.4 \%$} \\
\hline I strongly agree & & & & \\
\hline Total & 100.0 & 100.0 & 100.0 & 100.0 \\
\hline
\end{tabular}


These findings are significant because they expose conflictual trends within society. First, an important segment of respondents is in favor of using English as the main language of communication in public institutions (37.3\%) and in private companies (49.5\%), which implies that they welcome a more widespread use of English in the country; and arguably, this is likely to be done at the expense of Arabic. Second, another important segment of respondents is against the use of English as the main language of communication in public institutions (43.9\%) and in private companies (30.4\%), which, contrariwise, reflects a desire to contain the spread of English in the country and limit it to certain functions. Moreover, respondents seem to be divided over the negative impact English might have on Arabic and the local culture. First, some respondents believe that the spread of English in Bahrain is a threat to Arabic (45.8\%), which reflects their negative attitude towards the shifting linguistic landscape in Bahrain. Others (33.1\%), by contrast, do not consider that English is threatening Arabic, the official language of the country. Second, another significant part of respondents believes that English is menacing the local culture (42.4\%), which reflects a statistically quantifiable negative attitude towards English for cultural reasons. Thus, once again one could conclude that the Bahraini society is divided over the issue of the impact of English on both Arabic and the local culture. However, further research is required to investigate this issue and understand it thoroughly.

The above conclusion leads us to analyze the issue of language conflicts in Bahrain, although more data are required to understand what is really happening. The current study has proved that English is frequently used in three domains. These include (1) shops, malls, restaurants, and cafés (2) schools and university, and (3) work. Thus, one could logically conclude that these three domains represent the settings in which English and Arabic are conflicting the most. Additionally, using Nelde's definition of artificial language conflicts (Nelde, p 199), one could argue that English is gaining more ground at the expense of Arabic. This phenomenon is further illustrated by the findings of question 12 which asked respondents to report their use of English at home. Only 24.9\% of the respondents stated that they never use English at home. The others, however, revealed that they do use it at varying degrees. And when asked about their attitudes towards advising parents to use English to communicate with their children, $29.9 \%$ agreed, $12.3 \%$ were neutral, and 57.8\% disagreed. Overall, the majority believes that English should not displace Arabic as the main language of parental communication. Nonetheless, a statistically significant portion of the respondents believed that English should become the first language of family communication. This highly significant finding means that even in those contexts where Arabic is traditionally the only language of communication, English is making some concrete advances. This pushes us to conclude that, for some Bahrainis, English has gone beyond the status of a second language. For them, it is arguably becoming a first language, which subsequently means that Arabic is being displaced by English - even at home.

It is of paramount importance to remind, however, that this paper is mainly interested in analyzing the current status of English in Bahrain. Nonetheless, because English and Arabic are in direct contact, coming across elements of conflict should be expected. Van Oostendorp (2011) describes the advances English is making in the Netherlands and says, "It is clear that something is afoot: English is slowly but surely acquiring an even stronger place in our society. But how that is happening, how harmful it is, how people are responding to it - that we don't know." In the Middle East, this same idea is reiterated by the Moroccan researcher Mohamed Dahbi (2004) who argues that "the spread of English is getting out of hand in a way, because English is now the native language or the main school language of a very large and fast-growing Muslim population all over the world" ( $p$ 629). Such worried voices are heard in Bahrain as well. Tatan (2014) says, "One cannot accept the exclusion of Arabic as a means of communication with the community [...] Many citizens are complaining, either those who are good at English or those who have problems with it, because some national and local institutions, and even foreign companies, do not use Arabic in their transactions, as if they live in a western country and not an Arab country. The rule in those institutions is to use a foreign language. Arabic, however, has become an inferior language, and might not even be available for the public to use in their transactions."

\section{Conclusion}

The current paper suggests that the use of English in Bahrain is widespread in various domains. The phenomenon of the non-use of English clearly reflects the extensive use of English by Bahrainis in their daily lives. However, in terms of frequency, the results show that there are clear variations. In some domains and basic skills, the use of English was not that much frequent, which should not be regarded as a proof that English is not an important language in Bahrain. Because English in Bahrain is not the first language, one should not expect its use to be that much frequent in the country. Indeed, a high frequency of the use of English within a certain domain marks a low use of Arabic, which hints at issues of language shift and displacement.

In addition to the extensive use of English in Bahrain and its relative frequency, the results show that most Bahrainis view English as an important and attractive language. Nevertheless, it is necessary to note that such positive attitudes do not signal that all Bahrainis agree on how English should be used in the country. For instance, there are statistically significant divisions among Bahrainis concerning the use of English in public and private institutions, and its impact on Arabic and the local culture. These 
findings are very important because they entail some elements of language conflicts. English and Arabic in Bahrain are not solely conflicting in the various targeted domains, they are also doing so in people' minds.

All in all, this research paper has proved that English is spreading in Bahrain. This spread could be explained by referring to various factors which, together, have led to the current language situation. Globalization, official language policies, the size of the private sector, and gender are all factors which have facilitated the spread of English in the country. This paper also reveals that the language situation in Bahrain is still under the control of the government because, in two of the three major functions which English serves in Bahrain, two of these functions are under the direct control of the government. These are the occupational and educational functions, which implies that the government of Bahrain, through language planning, could easily alter the linguistic situation in the country.

\section{References}

[1] Bhushan, R. (2011). The Sociology of Language Teaching and Learning: Theory and Practice in Language Studies, 1(3), 309-311, March 2011. Retrieved from http://www.academypublisher.com/tpls/vol01/no03/tpls0103.pdf

[2] Central Informatics Organization. (2016). Cinema Visitors - (2005 - 2009). Retrieved from http://www.cio.gov.bh/cio_ara/English/Publications/Statistical\%20Abstract/ABS2009/CH8/12.pdf

[3] Central Informatics Organization. (2016). Education: Number of Teachers, Schools and Classes in Government and Public Schools. Retrieved from http://www.data.gov.bh/en/Dashboards

[4] Central Informatics Organization. (2016). Employed (15 Years +) by Age Groups, Nationality and Sex - 2013. Retrieved from http://www.cio.gov.bh/cio_ara/English//Publications/Statistical\%20Abstract/ABS2013/Ch11/1.pdf

[5] Dahbi, M. (2004). English and Arabic after 9/11. The Modern Language Journal, 88(4), 628-631. Retrieved from http://www.jstor.org/stable/3588597

[6] Directorate of Curricula. (2005). English Language Syllabus for Basic Education. Manama: Ministry of Education.

[7] Dornyei, Z. (2007). Research Methods in Applied Linguistics. Oxford: Oxford University Press.

[8] Education and Training Quality Authority. (2011). Higher Education Review Unit Institutional Review Report University of Bahrain Kingdom of Bahrain. Retrieved from https://www.qqa.edu.bh/En/Reports/UniReports/Second\%20Cycle\%20Reports/IRRUoBENS.pdf

[9] Edwards, A. (2014). ,.[ PhD dissertation]. University of Cambridge. Retrieved from https://alisonedwardsdotcom.files.wordpress.com/2012/04/phd-thesis_edwards.pdf

[10] Gomaa, Y. A. (2020). Language Policy in the Virtual Linguistic Landscape: The case of the Kingdom of Bahrain E-Government National Portal. Cadernos de Linguagem e Sociedade [Language and Society Notebooks]. Universidade de Brasília. Brazil: Thesaurus Editora de Brasilia Ltd. 21(2), 20-37. Retrieved from https://periodicos.unb.br/index.php/les/article/view/29354

[11] Gomaa, Y. A. (2017). Linguistic landscape in the Arabian Gulf: The case of Manama, Kingdom of Bahrain. Hermes Cairo University Center for Languages and Professional Translation, 2(2), 7-16.

[12] Graddol, D. (2006). English next (Vol. 62). London: British Council.

[13] Graddol, D. (2000). The Future of English?: The English Company (UK) Ltd (2000). Retrieved from http://www.britishcouncil.org/learning-eltfuture.pdf

[14] Kachru, B. B. (1985). Standards, codification and sociolinguistic realism: The English language in the outer circle. In R. Quirk \& H. Widdowson (Eds.), English in the world: Teaching and learning the language and literatures (pp. 11-30). Cambridge, UK: CUP.

[15] Labour Market Regulatory Authority. (2016). Table A. Estimated total employment by citizenship and sector: 2005 - 2016. Retrieved from http://blmi.Imra.bh/2016/06/data/Imr/Table_A.pdf

[16] Labov, W. (2001). Principles of linguistic change. Oxford: Blackwell.

[17] Ministry of Foreign Affairs. (2015). People and Culture. Retrieved from http://www.mofa.gov.bh/Default.aspx?tabid=130\&language=en-US

[18] Moeller, A. J. \& Catalano, T. (2015). Foreign Language Teaching and Learning. Faculty Publications: Department of Teaching, Learning and Teacher Education. Paper 200. Retrieved from http://digitalcommons.unl.edu/cgi/viewcontent.cgi?article=1199\&context=teachlearnfacpub

[19] Mollin, S. (2006). Euro-English. Assessing Variety Status. (Language in Performance 33) Tübingen: Narr. Extracted from: Forche, C. (2012). On the emergence of Euro-English as a potential European variety of English - attitudes and interpretations. Retrieved from: http://webcache.googleusercontent.com/search?q=cache:W1-DHZ-VOMcJ:hrcak.srce.hr/file/135148+\&cd=10\&hl=en\&ct=clnk\&gl=bh)

[20] Nelde, H. (2007). Language Conflict. The Handbook of Sociolinguistics. Coulmas, Florian (ed). Blackwell Publishing.

[21] Ringbom, H. (1980). On the Distinction between Second-Language Acquisition and Foreign-Language Learning. ABO Akademi Foundation. Retrieved from http://files.eric.ed.gov/fulltext/ED269973.pdf

[22] Schneider, E. W. (2007). Postcolonial English: Varieties around the world. Cambridge: Cambridge University Press. Retrieved from https://books.google.com.bh/books?id=QIE6zGSd8okC\&lpg=PP1\&dq=Postcolonial\%20English\%3A\%20Varieties\%20around\%20the\%20Wo rld\&pg=PP1\#v=onepage \&q=Postcolonial\%20English:\%20Varieties\%20around\%20the\%20World \&f=false

[23] Sharifian, F. (2009). English as an International Language: Perspectives and Pedagogical Issues. New York: Farzad Sharifian. Retrieved from http://www.nla.gov.au/openpublish/index.php/aral/article/viewFile/1999/2380

[24] Shura Council. (2015). Bahrain Brief. Retrieved from http://www.shura.bh/EN/INFORMATIONCENTER/Pages/Brief.aspx

[25] Tatan, H. (2014). Use Arabic because we are Arabs. Retrieved from http://alwatannews.net/PrintView.aspx?ID=8183\&Type=article

[26] VanPatten, B. \& Lee, J. F. (1990). Second Language Acquisition: Foreign Language Learning. Multilingual Matters, 58.

[27] Van Oostendorp, M. (2011). Moord en brand schreeuwen over het Engels. Retrieved from http://nederl.blogspot.co.uk/2011/12/col-moorden-brand-schreeuwen-over-het.html 